\title{
Physical activity and overweight/obesity in adult Mexican population. The Mexican National Health and Nutrition Survey 2006
}

\author{
Luz María Gómez, MSc, (1) Bernardo Hernández-Prado, DSc, (2) Ma del Carmen Morales, MSc, (1) \\ Teresa Shamah-Levy, MSc.(I)
}

\section{Gómez LM, Hernández-Prado B, Morales MC, Shamah-Levy T. Physical activity and overweight/obesity in adult Mexican population. \\ The Mexican National Health and Nutrition Survey 2006. Salud Publica Mex 2009;5I suppl 4:S62I-S629.}

\begin{abstract}
Objective. To determine the association between physical activity and overweight/obesity in Mexican adults. Material and Methods. Cross-sectional design. Adults 20 to 69 years of age were included in the Mexican National Health and Nutrition Survey 2006 (ENSANUT 2006). The dependent variable was overweight/obesity and the independent variable was recalled physical activity.Analysis was by logistic regression, adjusting for sex, age, residence area, region, socioeconomic status, indigenous ethnicity, smoking, schooling, work activity, alcohol consumption and sitting time. Results. Data from 15901 adults were analyzed. The prevalence of overweight/obesity had an inverse association with physical activity among men but not among women. Conclusions. The practice of physical activity was negatively associated with the prevalence of overweight/obesity only in adult men. These results underscore the importance of promoting physical activity to prevent and control overweight/obesity.
\end{abstract}

Key words: overweight; obesity; physical activity; adult; Mexico
Gómez LM, Hernández-Prado B, Morales MC, Shamah-Levy T. Actividad física y sobrepeso/obesidad

en población adulta mexicana.

Encuesta Nacional de Salud y Nutrición 2006.

Salud Publica Mex 2009;5I supl 4:S62I-S629.

\section{Resumen}

Objetivo. Determinar la asociación entre la actividad física y el sobrepeso/obesidad en adultos mexicanos. Material y métodos. Diseño transversal. Se incluyeron $1590 \mathrm{I}$ adultos de entre 20 a 69 años de edad, de la Encuesta Nacional de Salud y Nutrición 2006 (ENSANUT 2006). La variable dependiente fue sobrepeso/obesidad y la variable independiente fue la práctica de actividad física. Se usaron modelos de regresión logística ajustando por sexo, edad, área de residencia, región, nivel socioeconómico, indigenismo, tabaquismo, escolaridad, actividad laboral, consumo de alcohol y tiempo sentado. Resultados. Se estudió a I5 90 I adultos. La prevalencia de sobrepeso/obesidad tuvo una asociación inversa con la práctica de actividad física en hombres pero no en mujeres. Conclusiones. La práctica de actividad física se asoció negativamente con la prevalencia del sobrepeso/ obesidad únicamente en adultos hombres. Estos resultados subrayan la importancia de promover la actividad física para la prevención y control del sobrepeso/obesidad.

Palabras clave: sobrepeso; obesidad; actividad física; adulto; México

(I) Centro de Investigación en Nutrición y Salud. Instituto Nacional de Salud Pública. Cuernavaca, Morelos, México.

(2) Centro de Investigación en Salud Poblacional. Instituto Nacional de Salud Pública. Cuernavaca, Morelos, México. 
$\mathrm{O}^{\mathrm{b}}$ besity is a worldwide public health problem. The Norld Health Organization (WHO) estimates that there were 1600 million people overweight in 2005, and there will be 2300 million overweight adults and more than 700 million adults with obesity by $2015 .{ }^{1}$ Obesity is a risk factor for the development of diseases such as diabetes, heart disease, hypertension, some types of cancer, etc. Those diseases account for $60 \%$ of all causes of death in the world. This percentage could amount to $73 \%$ by year 2020 , affecting mainly people aged 18 to 70 years. $^{2}$

In Mexico, there is a high prevalence of overweight/ obesity. According to data from the Mexican National Health and Nutrition Survey 2006 (ENSANUT 2006), prevalence of overweight/ obesity in women older than 20 years is $71.9 \%$, and in men it is $66.7 \%$. Also, there is a high prevalence of hypertension (30.8\%), diabetes, and other chronic diseases. ${ }^{3}$

Physical activity is defined as any body movement involving energy expenditure, and it is the component of energy expenditure which varies the most, being to a certain extent expressed at will. ${ }^{4}$ Physical activities play an important role in the prevention of chronic diseases; they are regarded as a protection factor against ischemic cardiopathy, diabetes mellitus, stroke, osteoporosis, mental disorders, and some types of cancer. ${ }^{5}$ Moreover, an inverse association between intense physical activities and obesity has been found. ${ }^{6}$

Several studies have shown that performing physical activities on a regular basis (at least 30 minutes a day of moderate intensity physical activity) enhances life quality and health condition. Furthermore, they contribute to prevent and control cardiovascular diseases, hypertension, diabetes, obesity, etc. ${ }^{7}$ According to $\mathrm{WHO}$ estimations, up to $80 \%$ of diabetes cases and cardiovascular diseases and up to $30 \%$ of some types of cancer ${ }^{8}$ could be avoided by establishing preventive interventions such as improvement of diet quality and physical activity.

Regarding physical activity in Mexico, an analysis from the 1999 National Nutrition Survey (NNS-99) ${ }^{4}$ found that sports practice is not a common type of physical activity in women of childbearing age, particularly in those older than 20 years and those with low schooling.

However, nationwide there is no information about practice levels of physical activity in adults. Data are available only from youth living in certain cities and from women of childbearing age countrywide, and show low levels of physical activity. ${ }^{9}$ There is also no information based on large-scale population studies in Mexico on the association between physical activity practice and obesity. Hence, this study aimed at documenting the levels of physical activity and evaluated the relationship between physical activity and overweight/ obesity in Mexican adults in order to design strategies and interventions that help prevent and control this public health problem.

\section{Material and Methods}

Design: The ENSANUT 2006 was a cross-sectional, probabilistic survey with a stratified and clustered sampling design, representative at the national, regional, and state levels. Its design enabled the analysis of information on health and nutrition status of the Mexican population, and on quality and response of health services, policies and programs. The methodology of the ENSANUT 2006 has been described in detail elsewhere. ${ }^{10}$

Subjects: Information from 48304 households nationwide was collected in the ENSANUT 2006. The physical activity questionnaire was administered to a subsample of 20360 men and women aged 20 to 99 years selected at random. We conducted the analysis with a sample of men and women aged 20 to 69 years who lived in the selected households at the time of the survey. Adults with undernutrition, low weight, incapable of performing physical activity, and those older than 69 years were excluded from the analysis because the questionnaire used to measure physical activity, which will be described later, was designed to be applied to adults aged 15 to 69 years.

Procedure: Data were collected in selected households between August and September 2005 by interviewers trained previously. Objectives, procedures, risks and benefits of the study were explained in detail to every potential participant. Those who agreed to participate were asked to sign or fingerprint an informed consent. The protocol for this study was approved by the Research, Biosafety, and Ethics Committees of the National Public Health Institute: INSP, in Cuernavaca, Mexico.

\section{Outcome variables}

The outcome variable for this study was overweight or obesity based on body mass index (BMI) (weight in kilograms/height in meters ${ }^{2}$ ). Anthropometric measures were taken by previously standardized personnel. Standardization procedures were carried out before collecting data to minimize technical measurement errors using the Habicht technique. ${ }^{11}$ Weight was measured with Tanita electronic scales with $100 \mathrm{~g}$ accuracy. Height was measured with stadimeters with capacity for 2 meters and accuracy to $1 \mathrm{~mm}$. 
Adults were classified according to their nutrition status using the cutoff points recommended by the WHO for BMI as follows: undernutrition (BMI < 18.5), adequate nutrition status (BMI from 18.5 to 24.9), overweight (BMI from 25.0 to 29.9), and obesity (BMI $\geq 30.0) .{ }^{12} \mathrm{BMI}$ values between 10 and $58 \mathrm{~kg} / \mathrm{m}^{2}$ were considered as valid.

\section{Exposure measures}

Physical activity and sitting time: Data on hours weekly adults performed physical activity or remained sitting was collected using the short version of the International Physical Activity Questionnaire ${ }^{13}$ (IPAQ), which is an instrument validated and used worldwide for the measurement of physical activity.

Vigorous physical activity was defined as a group of activities requiring an energy expenditure equal or higher than 6 METs/hour* (physical activity energy expense unit); that is, those that demand a considerable energy expenditure. This category included activities such as aerobics, fast bicycle riding, lifting heavy objects, digging, farm work, or activities that involve more difficult breathing than normal. Moderate physical activity was defined as a group of activities requiring less energy expenditure (between 3.0 and 5.9 METs/ hour); those in which breathing is a little more difficult than normal, such as lifting light objects or riding a bicycle at regular speed. It did not include walking. Time spent walking was classified into a different category and included walking in the work place, at home, from one place to another, or walking during leisure time, for sports, exercise or pleasure for periods of time of at least 10 minutes. Sedentary activities that require less energy expenditure were also defined, such as time adults spent sitting at work or at home, studying, watching TV, or resting. The methodology used in the ENSANUT 2006 identified time devoted to vigorous and moderate physical activity, walking, and sitting time, except sleeping time. Information on days, hours, and minutes devoted to vigorous and moderate physical activity and walking was collected. Once time spent performing each type of physical activity, in minutes per week, was obtained, MET values were calculated by multiplying the minutes per week of time devoted to moderate and vigorous

\footnotetext{
* A unit of metabolic equivalent (MET) represents a multiple of the oxygen consumption at rest, which in turn correspond to $3.5 \mathrm{~mL}$ $\mathrm{O}^{2} / \mathrm{kg}$ min-1. For example if one person doing exercise show an expenditure of $10 \mathrm{MET}$, this means that hew has consumed 10 times the oxygen amount which normally would consume being at rest.
}

physical activity and walking by the values suggested by the IPAQ data processing guide (3.3 for walking, 4.0 for moderate, and 8.0 for vigorous physical activity). Classification of physical activity categories was as follows: low < $600 \mathrm{METs}$ / minutes/week; moderate $\geq 600$ to $<3000 \mathrm{METs} /$ minutes/week; high $\geq 3000 \mathrm{METs}$ / minutes/week. The above categories permitted simple identification of active or sedentary lifestyle patterns.

\section{Covariates}

Socioeconomic status: A socioeconomic status index was constructed using variables on housing conditions and possession of appliances and other goods. ${ }^{14}$ Three categories were used to define the socioeconomic level of adults (low, medium, high) according to tertile distribution for this index.

Socio-demographic characteristics: Among the independent variables, some characteristics that could be associated with physical activity and overweight/obesity were studied, such as age and living in rural or urban areas (population over 2500 inhabitants). Adults were classified according to four regions of residence: north, center, Mexico City, and south. . Data on tobacco and alcohol consumption and on the condition of being a speaker of an indigenous language were also obtained.

\section{Statistical analysis}

The ENSANUT 2006 was designed as a multistage, clustered sampling study. Therefore, some adjustments were made in the analyses according to the probability of every adult being included in the sample by using a weighting factor. For controlling the design effect produced by the cluster of observations in this sample, the SVY module for complex samples in the STATA program version 9.2 was used. ${ }^{\ddagger}$

An exploratory analysis of data was carried out to identify implausible or extreme observations, to describe the population characteristics, and to calculate time devoted to each type of physical activity. Implausible physical activity values were defined as those with sum

\footnotetext{
* North region included the states of Baja California, South Baja California, Coahuila, Chihuahua, Durango, Nuevo León, Sonora and Tamaulipas; Center region: Aguascalientes, Colima, Guanajuato, Jalisco, Estado de Mexico (excluding Mexico City's metropolitan area) Michoacan, Morelos, Nayarit, Queretaro, San Luis Potosi, Sinaloa, and Zacatecas; Mexico City and its metropolitan area; and South region: Campeche, Chiapas, Guerrero, Hidalgo, Oaxaca, Puebla, Quintana Roo, Tabasco, Tlaxcala, Veracruz, and Yucatan.

₹ Stata Corp. Intercooled Stata 9.2 College Station Texas, USA, 2006.
} 
of time devoted to different activities in one day that resulted in a value more than 24 hours.

Since the outcome variable was BMI as indicator of nutritional status, linear regression models were adjusted for the dependent variable, taking as main exposure variable the categories of physical activity (low, moderate, or high) based on METs according to the IPAQ, and controlling for sex, age, residence area (rural or urban), region of the country (north, center, Mexico City, south), socioeconomic status (low, middle, high), indigenous ethnicity, smoking, schooling, work activity, alcohol consumption, and sitting time. Different models were estimated for each sex.

In addition, a logistic regression model was fitted to the data to test the possibility of being overweight or obese based on physical activity categories (low, moderate, or high, in accordance with the IPAQ), controlling for confounding variables. A significance level of 0.05 was considered as statistically significant for all the analysis.

\section{Results}

Information on physical activity was collected from 20360 Mexican men and women. Out of those, 1390 adults were excluded as they did not answer all the questions related to physical activity or gave implausible information. Another 3069 adults were also excluded whose BMI data were incomplete, and older adults over 69 years old were not considered because the IPAQ questionnaire used was only validated for individuals aged 15 to 69 years.

Thus, the final sample included 15901 adults, which represented 19756134 Mexican adults using the expansion factor for this survey. Table I presents descriptive information for the sample. Most individuals were women $(63.3 \%)$ with a mean age of $39.9 \pm 12.9$ years. Men represented $36.7 \%$ of the sample, with a mean age of $41.6 \pm 13.5$ years. The majority of individuals, both men and women, were more than 30 years old (76.2\% and $74.8 \%$, respectively). BMI mean was $27.1 \pm$ 4.3 in men and $28.6 \pm 5.4$ in women. A total of $65.7 \%$ of men and $72.1 \%$ of women were overweight or obese. With respect to schooling, $12.0 \%$ of the subjects had no formal education, $46.8 \%$ completed primary school, $21.4 \%$ middle school, and $19.9 \%$ high school or higher. In addition, $10.6 \%$ spoke an indigenous language, $25.0 \%$ of adults smoked, and $29.8 \%$ consumed alcohol at the time of the survey, although most consumption of tobacco and alcohol was reported in men $45.5 \%$ and $53.3 \%$, respectively) compared with women (13.0\% and $16.1 \%$, respectively). Most adults were of low socioeconomic status $(42.0 \%)$, and lived in rural areas $(66.2 \%)$.
Table II presents descriptive information for physical activity. Mean METs/minutes/week for vigorous physical activity was greater in men than in women (3322 \pm 4238 and $1135 \pm 2567$, respectively) but it was not so for moderate physical activity (means $1890 \pm 2076$ and $2534 \pm 2088$, respectively). Mean METs/minutes/ week for walking was $1219 \pm 1361$ for both sexes, and for sitting time, it was $1111 \pm 913$. Most adults (66.4\%) were in the high physical activity practice category, $20.6 \%$ were in the moderate category and $13.0 \%$ in the low category.

According to data on men's nutrition status, the greatest proportion of overweight/obesity was found in those aged 40 to 49 years (73.8\%). Men with obesity had less METs/minutes/week physical activity (vigorous, moderate, and walking) and remained sitting for a longer time compared with men with adequate BMI. Most men in the low physical activity category were overweight or obese, compared with men with adequate BMI (17.4\% and $9.1 \%$, respectively). As for the high physical activity category, the greatest proportion corresponded to men with adequate BMI compared with overweight or obese men ( $73.7 \%$ and $64.2 \%$, respectively) (Table III A).

Concerning women, the greatest proportion of overweight/obesity was found in those aged 50 to 59 years $(82.6 \%)$. Overweight women had more METs/ minutes/week of vigorous physical activity and of walking compared with women whose BMI was adequate, and with those with obesity. Likewise, women with obesity had a greater METs/minutes/week of moderate physical activity and reported more sitting time, compared with women whose BMI was adequate, and with those with overweight. The majority of women in the low and high physical activity categories were those with obesity ( $14.3 \%$ and $65.8 \%$, respectively), compared with women whose BMI was adequate and with those with overweight (Table III B). On the other hand, according to the IPAQ significant associations between overweight/obesity and the physical activity practice categories were found only in adult men, adjusting for confounding variables (age, residence area, region of the country, socioeconomic status, indigenous ethnicity, smoking, schooling, work activity, alcohol consumption, and sitting time) (See table IV). Adult men in the high physical activity category were $27 \%$ less likely to be overweight or obese compared with men in the low category (OR $0.73,95 \%$ CI; 0.55 , 0.96). Adult men of middle and high socioeconomic status were $57 \%$ more likely to be overweight or obese (OR 1.57, 95\% CI; 1.28, 1.92, and OR 1.66, 95\% CI; 1.22, 2.25 , respectively) compared with adult men of low socioeconomic status. With regard to place of residence, adult men living in urban areas were 32\% more likely 
Table I

Socio-demographic characteristics of MeXicAN ADULTS AGed 20 to 69 Years.

MeXIco, ENSANUT 2006

\begin{tabular}{|c|c|c|c|c|c|c|c|c|c|}
\hline \multirow[t]{3}{*}{ Characteristics } & \multicolumn{6}{|c|}{ Sex } & \multicolumn{3}{|c|}{ Total } \\
\hline & \multicolumn{3}{|c|}{ Men } & \multicolumn{3}{|c|}{ Women } & \multirow{2}{*}{$\begin{array}{l}\text { Weighted n } \\
15901\end{array}$} & \multirow{2}{*}{$\begin{array}{l}\text { Expanded n } \\
19756 \quad 134\end{array}$} & \multirow{2}{*}{$\begin{array}{l}\text { Total } \\
100\end{array}$} \\
\hline & 5470 & 7246221 & 36.7 & 10431 & 12509913 & 63.3 & & & \\
\hline Age (years $\pm S D$ )* & 5470 & 7246221 & $41.6 \pm 13.5$ & 10431 & 12509913 & $40.0 \pm 12.9$ & 15901 & $19756 \quad 134$ & $40.6 \pm 13.2$ \\
\hline $\mathrm{BMI} \pm \mathrm{SD}$ & 5470 & 7246221 & $27.1 \pm 4.3$ & 10431 & 12509913 & $28.6 \pm 5.4$ & 15901 & $19756 \quad 134$ & $28.1 \pm 5.1$ \\
\hline
\end{tabular}

Nutrition status (\%)

\begin{tabular}{|c|c|c|c|c|c|c|c|c|c|}
\hline Undernutrition & 72 & 112355 & 1.5 & 105 & 144930 & 1.1 & 177 & 257285 & 1.3 \\
\hline Normal & 1755 & 2413733 & 32.8 & 2659 & 3390281 & 26.8 & 4414 & 5804014 & 29.0 \\
\hline Overweight & 2423 & 3245654 & 44.1 & 3920 & 4715988 & 37.3 & 6343 & 7961642 & 39.8 \\
\hline Obesity & 1292 & I 586834 & 21.6 & 3852 & 4403644 & 34.8 & 5144 & 5990478 & 29.9 \\
\hline
\end{tabular}

Smoking (\%)

\begin{tabular}{lrrrrrrrrr} 
Yes & 2373 & 3300015 & 45.5 & 1063 & 1619052 & 12.9 & 3436 & 4919067 & 24.9 \\
\hline No & 3096 & 3945954 & 54.5 & 9368 & 10890861 & 87.1 & 12464 & 14836815 & 75.1
\end{tabular}

Indigenous ethnicity (\%)

\begin{tabular}{rrrrrrrrrr} 
Yes & 648 & 711554 & 9.8 & 1280 & 1388927 & 11.10 & 1928 & 2100481 & 10.6 \\
\hline No & 4822 & 6534667 & 90.2 & 9151 & 11120986 & 88.90 & 13973 & 17655653 & 89.4
\end{tabular}

Alcohol consumption (\%)

\begin{tabular}{rrrrrrrrrr} 
Yes & 2956 & 3861594 & 53.3 & 1506 & 2018219 & 16.1 & 4462 & 5879813 & 29.8 \\
\hline No & 2513 & 3384375 & 46.7 & 8925 & 10491694 & 83.9 & 11438 & 13876069 & 70.2
\end{tabular}

Schooling level $n(\%)$

\begin{tabular}{lrrrrrrrrr} 
None & 544 & 699222 & 12.6 & 1314 & 1668708 & 13.3 & 1858 & 2367930 & 12.0 \\
\hline Elementary & 2631 & 3155517 & 51.8 & 5399 & 6080814 & 48.6 & 8030 & 9236331 & 46.8 \\
\hline Middle & 1227 & 1669642 & 21.9 & 2290 & 2555932 & 20.4 & 3517 & 4225574 & 21.4 \\
\hline High school or over & 1068 & 1721840 & 13.6 & 1425 & 2200851 & 17.6 & 2493 & 3922691 & 19.9
\end{tabular}

Socioeconomic status $n(\%)^{\ddagger}$

\begin{tabular}{|c|c|c|c|c|c|c|c|c|c|}
\hline Low & 2623 & 2896976 & 40.1 & 5190 & 5364553 & 43.1 & 7813 & 8261529 & 42.0 \\
\hline Middle & 1708 & 2171229 & 30.1 & 3356 & 4015391 & 32.2 & 5064 & 6186620 & 31.4 \\
\hline High & 1129 & 2157530 & 29.9 & 1847 & 3070435 & 24.6 & 2976 & 5227965 & 26.6 \\
\hline
\end{tabular}

Region $n(\%)$

\begin{tabular}{|c|c|c|c|c|c|c|c|c|c|}
\hline North & 1106 & I 159098 & 16.0 & $|87|$ & 1919390 & 15.3 & 3224 & 3078488 & 15.6 \\
\hline Center & 1896 & I 748746 & 24.1 & 3769 & 3060224 & 24.4 & 6176 & 4808970 & 24.3 \\
\hline Mexico City and metropolitan area & 336 & 1743212 & 24.1 & 626 & 2950318 & 23.5 & 1023 & 4693530 & 23.8 \\
\hline South & 2132 & 2595165 & 35.8 & 4165 & 4579981 & 36.6 & 6769 & $7|75| 46$ & 36.3 \\
\hline
\end{tabular}

Area $n(\%)$

\begin{tabular}{llllllllll} 
Urban & 2280 & 2396833 & 33.1 & 4362 & 4278600 & 34.2 & 6642 & 6675433 & 33.8 \\
\hline Rural & 3190 & 4849388 & 66.9 & 6069 & 8231313 & 65.8 & 9259 & 13080701 & 66.2
\end{tabular}

$*$ Mean \pm Standard deviation (or as specified)

$\ddagger$ Based on housing conditions and ownership of home appliances and other goods, using principal components analysis ${ }^{14}$ 
Table II

Physical activity of Mexican adults aged 20 to 69 years. Mexico, ENSANUT 2006

\begin{tabular}{|c|c|c|c|c|c|c|c|c|c|}
\hline \multirow[t]{3}{*}{ Characteristics } & \multicolumn{6}{|c|}{ Sex } & \multicolumn{3}{|c|}{ Total } \\
\hline & \multicolumn{3}{|c|}{ Men } & \multicolumn{3}{|c|}{ Women } & \multirow[b]{2}{*}{ Weighted $n$} & \multirow[b]{2}{*}{$\begin{array}{c}\text { Expanded } \\
n\end{array}$} & \multirow[b]{2}{*}{ Total } \\
\hline & Weighted $n$ & Expanded $n$ & Mean $\pm S D$ & Weighted $n$ & $\begin{array}{c}\text { Expanded } \\
n\end{array}$ & Mean $\pm S D$ & & & \\
\hline $\begin{array}{l}\text { Vigorous physical activity (METs/ } \\
\text { minutes/week } \pm \text { SD)* }\end{array}$ & 5470 & 7246221 & $3322 \pm 4238$ & 10431 & 12509913 & $1135 \pm 2567$ & 15901 & $19756 \quad 134$ & $1937 \pm 3445$ \\
\hline $\begin{array}{l}\text { Moderate physical activity (METs/ } \\
\text { minutes/week } \pm \text { SD) }\end{array}$ & 5470 & 7246221 & $1890 \pm 2076$ & 10431 & 12509913 & $2534 \pm 2088$ & 15901 & 19756134 & $2298 \pm 2107$ \\
\hline $\begin{array}{l}\text { Walking (METs/minutes/week } \pm \\
\text { SD) }\end{array}$ & 5470 & 7246221 & $1383 \pm 1124$ & 10431 & 12509913 & $1124 \pm 1302$ & 15901 & 19756134 & $|2| 9 \pm|36|$ \\
\hline $\begin{array}{l}\text { Total physical activity (Vigorous, mod- } \\
\text { erate and walking in METs/minutes/ } \\
\text { week } \pm \text { SD) }\end{array}$ & 5470 & 7246221 & $6596 \pm 5011$ & 10431 & 12509913 & $4795 \pm 3719$ & 15901 & 19756134 & $5455 \pm 4327$ \\
\hline Sitting time (minutes/week \pm SD) & 5470 & 7246221 & $1227 \pm 1016$ & 10431 & 12509913 & $1044 \pm 840$ & $1590 \mid$ & 19756134 & $1111 \pm 913$ \\
\hline
\end{tabular}

Physical activity categories (\%) (According to the IPAQ in METs/minutes/Week)

\begin{tabular}{lrrrrrrrrr} 
Low & 607 & 865663 & 11.9 & 1314 & 1702073 & 13.6 & 1921 & 2567736 & 13.0 \\
\hline Moderate & 899 & 1327722 & 18.3 & 2244 & 2745724 & 21.9 & 3143 & 4073446 & 20.6 \\
\hline High & 3964 & 5052836 & 69.7 & 6873 & 8062116 & 64.4 & 10837 & 13 II4 952 & 66.4 \\
* Mean \pm Standard deviation (or as specified) & & & & & & & & \\
\hline
\end{tabular}

to be overweight or obese compared with those living in rural areas (OR 1.32, 95\% CI; 1.08, 1.60). Adult men with primary schooling were $36 \%$ more likely to be overweight or obese compared with those without formal education (OR 1.36, 95\% CI; 1.06, 1.76). Also, linear tendency was observed for a decreasing probability of being overweight or obese from 50 years of age onward in this population. The remaining socio-demographic variables studied did not show any significant association with the prevalence of obesity or overweight. Men with adequate BMI spent more time doing vigorous physical activity than men who were overweight/ obese; conversely, women with overweight/obesity reported more time doing moderate physical activity than women whose BMI was adequate (Figure 1).

\section{Discussion}

The results of this study show that physical activity was inversely associated with the prevalence of overweight/ obesity in a representative sample of Mexican adults. Such association was observed only among adult men, but not among women. This is the first study, to our knowledge, documenting this finding in a nationwide probabilistic sample of Mexican adults of both sexes.

We also show that men but not women in high and middle socioeconomic status are more likely to be overweight or obese. Little physical activity in women, particularly vigorous and moderate, may account for that effect on the association. There also exists the possibility of overestimation of physical activity in women with overweight/obesity, as has been documented in other studies. ${ }^{15-19}$

The results are plausible given the observed trend towards decrease in physical activity owing to the sedentary nature of many work activities, the changes in transportation methods and sprawling urbanization. In addition, the increase of energy-dense foods, rich in fat and sugar, has brought about an imbalance between intake and energy expenditure. The strength of this study stems from being a probabilistic, nationwide survey. Also, physical activity was measured through the IPAQ questionnaire, an internationally validated instrument for measuring physical activity in individuals 15 to 
Table III A

Characteristics of adult men according to their nUtrition status. Mexico, ENSANUT 2006

\begin{tabular}{|c|c|c|c|}
\hline \multirow{2}{*}{ Characteristics } & \multicolumn{3}{|c|}{ BMI } \\
\hline & Normal & Overweight & Obesity \\
\hline$N(\%)^{*}$ & $1755(33.3)$ & $2423(44.79)$ & $1292(21.90)$ \\
\hline Age (years $\pm S D$ ) & $39.3 \pm 14.2$ & $42.55 \pm 13.26$ & $43.05 \pm 12.58$ \\
\hline $\mathrm{BMI} \pm \mathrm{SD}$ & $22.7 \pm 1.6$ & $27.34 \pm 1.4 \mid$ & $33.36 \pm 3.04$ \\
\hline \multicolumn{4}{|l|}{ Age (years $n \%$ ) } \\
\hline 20 to 29 & $507(48.1)$ & $422(37.1)$ & $179(\mid 4.9)$ \\
\hline 30 to 39 & $462(30.3)$ & $668(46.0)$ & $380(23.7)$ \\
\hline 40 to 49 & $324(26.2)$ & $632(49.2)$ & $342(24.6)$ \\
\hline 50 to 59 & $248(28.8)$ & $397(45.4)$ & $237(25.8)$ \\
\hline 60 to 69 & $214(30.9)$ & $304(47.8)$ & $154(21.4)$ \\
\hline Vigorous physical activity (METs/minutes/week \pm SD) & $353 \mid \pm 4278$ & $3412 \pm 4289$ & $2818 \pm 4032$ \\
\hline Moderate physical activity (METs/minutes/week \pm SD) & $1928 \pm 2069$ & $1887 \pm 2089$ & $184 \mid \pm 2063$ \\
\hline Walking (METs/minutes/week \pm SD) & $1426 \pm 1443$ & $1434 \pm 1475$ & $1210 \pm 1367$ \\
\hline Total physical activity (Vigorous, moderate and walking in METs/minutes/week \pm SD) & $6886 \pm 4940$ & $6734 \pm 5093$ & $587 \mid \pm 4882$ \\
\hline Sitting time (minutes/week $\pm S D$ ) & $1149 \pm 892$ & $1204 \pm 1018$ & $1391 \pm 1163$ \\
\hline
\end{tabular}

Physical activity categories (\%) (According to the IPAQ in METs/minutes/Week)

\begin{tabular}{|c|c|c|c|}
\hline Low & $154(9.1)$ & $253(11.4)$ & $200(17.4)$ \\
\hline Moderate & $277(17.1)$ & 403 (19.2) & $219(18.4)$ \\
\hline High & I 324 (73.8) & $1767(69.4)$ & $873(64.2)$ \\
\hline
\end{tabular}

Table III B

Characteristics of adult women according to their nUtrition status. Mexico, enSANUT 2006

\begin{tabular}{|c|c|c|c|}
\hline \multirow[t]{2}{*}{ Characteristics } & \multicolumn{3}{|c|}{$B M I$} \\
\hline & Normal & Overweight & Obesity \\
\hline$\underline{N}(\%)^{*}$ & $2659(27.1)$ & $392(37.7)$ & $3852(35.2)$ \\
\hline Age (years $\pm S D$ ) & $36.0 \pm 13.2$ & $40.2 \pm 12.6$ & $42.8 \pm 12.2$ \\
\hline $\mathrm{BMI} \pm \mathrm{SD}$ & $22.6 \pm 1.6$ & $27.5 \pm 1.4$ & $34.4 \pm 3.9$ \\
\hline \multicolumn{4}{|l|}{ Age (years n \%) } \\
\hline 20 to 29 & $946(43.8)$ & $823(34.2)$ & $591(22.0)$ \\
\hline 30 to 39 & $787(25.8)$ & $1333(40.0)$ & $1247(34.3)$ \\
\hline 40 to 49 & $431(18.4)$ & $882(39.4)$ & $984(42.2)$ \\
\hline 50 to 59 & $259(17.4)$ & $516(38.1)$ & $621(44.5)$ \\
\hline 60 to 69 & $236(23.0)$ & $366(35.9)$ & $409(41.1)$ \\
\hline Vigorous physical activity (METs/minutes/week \pm SD) & $1092 \pm 2556$ & $1258 \pm 2705$ & $1037 \pm 2416$ \\
\hline Moderate physical activity (METs/minutes/week \pm SD) & $2442 \pm 2086$ & $2524 \pm 2072$ & $2616 \pm 2103$ \\
\hline Walking (METs/minutes/week \pm SD) & $1133 \pm 1275$ & $1155 \pm 1310$ & $1084 \pm 1312$ \\
\hline Total physical activity (Vigorous, moderate and walking in METs/minutes/week \pm SD) & $4669 \pm 3745$ & $4938 \pm 3808$ & $4738 \pm 3596$ \\
\hline Sitting time (minutes/week \pm SD) & $1018 \pm 833$ & $1027 \pm 820$ & $1083 \pm 866$ \\
\hline
\end{tabular}

\section{Physical activity categories (\%) (According to the IPAQ in METs/minutes/Week)}

\begin{tabular}{|c|c|c|c|}
\hline Low & $323(13.5)$ & $472(13.0)$ & $519(14.3)$ \\
\hline Moderate & $615(24.9)$ & $813(21.8)$ & $816(19.8)$ \\
\hline High & $172 \mid(6 \mid .6)$ & $2635(65.2)$ & $2517(65.8)$ \\
\hline \multicolumn{4}{|c|}{$*_{n}$ expanded for women 12509913} \\
\hline
\end{tabular}


Table IV

LOGISTIC REGRESSION MODEL FOR OVERWEIGHT AND OBESITY AND ITS RELATION WITH PHYSICAL activity categories in Mexican adults. Mexico, ENSANUT 2006

Characteristics

\begin{tabular}{|c|c|c|c|}
\hline \multicolumn{4}{|c|}{ Sex } \\
\hline & & & \\
\hline Adjusted OR* & $95 \% \mathrm{Cl}$ & Adjusted OR* & $95 \% \mathrm{Cl}$ \\
\hline
\end{tabular}

\begin{tabular}{lllll} 
Low physical activity category & $\mathrm{I}$ & $\mathrm{I}$ & \\
\hline Moderate physical activity category & 0.81 & $(0.58,1.13)$ & 0.80 & $(0.62,1.04)$ \\
\hline High physical activity category & 0.73 & $(0.55,0.96)$ & 1.03 & $(0.82,1.3)$
\end{tabular}

Age categories

\begin{tabular}{llllll}
20 to 29 years & I & & I & \\
\hline 30 to 39 years & 2.09 & $(1.63,2.69)$ & 2.16 & $(1.81,2.58)$ \\
\hline 40 to 49 years & 2.52 & $(1.91,3.33)$ & 3.26 & $(2.64,4.02)$ \\
\hline 50 to 59 years & 2.19 & $(1.59,3.01)$ & 3.58 & $(2.78,4.61)$ \\
\hline 60 to 69 years & 2.16 & $(1.58,2.97)$ & 2.55 & $(1.95,3.35)$
\end{tabular}

Work status

\begin{tabular}{llllll} 
Not working & 1 & & I & \\
\hline Working & 1.29 & $(1.01,1.65)$ & 1.23 & $(I .01, I .48)$
\end{tabular}

Schooling level

\begin{tabular}{|c|c|c|c|c|}
\hline None & 1 & & I & \\
\hline Elementary & 1.37 & $(1.06,1.76)$ & 1.37 & $(1.11,1.69)$ \\
\hline Middle & 1.26 & $(0.94,1.7)$ & 1.23 & $(0.94,1.59)$ \\
\hline High school or over & 0.91 & $(0.64,1.32)$ & 0.77 & $(0.58,1.03)$ \\
\hline egion & 1.02 & $(0.95,1.09)$ & 0.90 & $(0.84,0.95)$ \\
\hline
\end{tabular}

Area $n$

\begin{tabular}{llllll} 
Urban & 1 & \multicolumn{1}{l}{} & \\
\hline Rural & 1.32 & $(1.09,1.61)$ & 1.26 & $(1.08,1.47)$
\end{tabular}

Alcohol consumption

\begin{tabular}{lllll} 
No & I & & \multicolumn{1}{l}{} & \\
\hline Yes & 0.93 & $(0.79, I . I)$ & I.03 & $(0.83, I .27)$
\end{tabular}

Smoking

\begin{tabular}{llllll} 
No & I & & \multicolumn{1}{l}{} & \\
\hline Yes & 0.91 & $(0.76, I . I)$ & 0.84 & $(0.62, I .15)$
\end{tabular}

Socioeconomic status

\begin{tabular}{|c|c|c|c|c|}
\hline Low & I & & I & \\
\hline Middle & 1.57 & $(1.29,1.93)$ & 1.44 & $(1.22,1.7)$ \\
\hline High & 1.66 & $(1.22,2.26)$ & 0.98 & $(0.78,1.23)$ \\
\hline Sitting time (hr) & 1.03 & $(0.99,1.08)$ & 1.06 & $(\mathrm{I} .0 \mathrm{I}, \mathrm{I} . \mathrm{I})$ \\
\hline
\end{tabular}




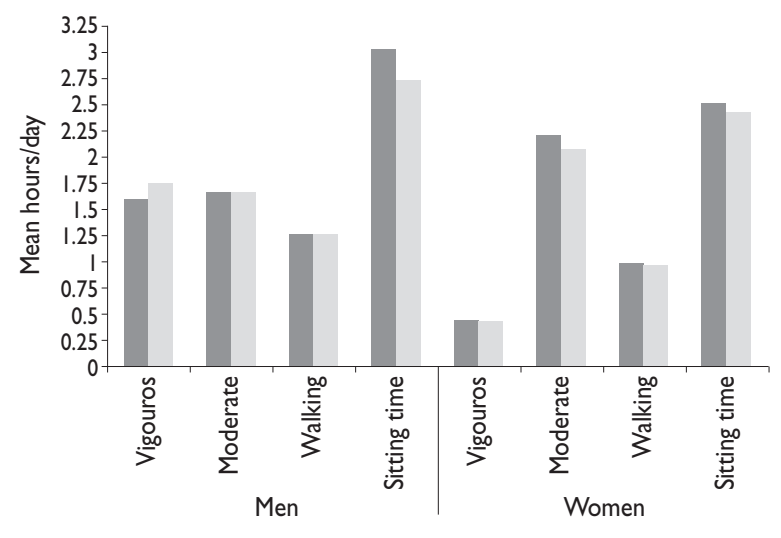

Overweight/Obesity Normal BMI

* Means of vigorous and moderate physical activity, walking and sitting time in Mexican adults, by sex and BMI, classified as overweight/obesity and normal BMI, hours/day

Figure I. Means of vigorous and moderate physical ACTIVITY, WALKING AND SITTING TIME IN MEXiCAN ADULTS. MeXIco, ENSANUT 2006

69 years old, which can be used in prevalence studies based on national populations. As a standard indicator, the IPAQ questionnaire is recommended for making comparisons within a country, between countries, and worldwide.

This study has some limitations that should be considered for the interpretation of results. Because of its cross-sectional design, causal inferences are difficult to make, so it is possible to identify only some associations between socio-demographic characteristics, physical activity of adults, and overweight/obesity. However, this information is valuable as it documents the association between physical activity and overweight/ obesity and helps to identify groups that perform less physical activity (particularly intense physical activity in women, as has been documented in other studies); ${ }_{4}^{4}$ this underscores the necessity of focusing interventions on that population group to promote physical activity. In conclusion, physical activity was inversely associated with overweight/obesity in a representative sample of Mexican adult men. Therefore, encouraging vigorous or moderate physical activity and reducing sedentary activities, along with the promotion of a healthy diet, are necessary steps aimed at preventing and controlling overweight/ obesity in both adolescents and adults, thus decreasing the risk of chronic diseases in those population groups.

\section{References}

I. Organización Mundial de la Salud. Obesidad y sobrepeso. Nota descriptiva No 31 I. Septiembre de 2006. [Consulted 2009 April 6]. Available at: http://www.who.int/mediacentre/factsheets/fs3 I / es/index.html). 2. Organización Panamericana de la Salud. Estrategia Mundial sobre Alimentación Saludable,Actividad Física y Salud (DPAS). Plan de Implementación en América Latina y el Caribe. 2006-2007.Washington, DC:WHO, 2006.

3. Olaiz-Fernández G, Rivera-Dommarco J, Shamah-Levy T, Rojas R, Villalpando-Hernández S, Hernández-Ávila M, et al. Encuesta Nacional de Salud y Nutrición 2006. Cuernavaca, México: Instituto Nacional de Salud Pública, 2006.

4. Hernández B, de Haene J, Barquera S, Monterrubio E, Rivera J, Shamah $\mathrm{T}$, et al. Factors associated with physical activity among Mexican women of childbearing age. Rev Panam Salud Publica 2003;14(4):235-245.

5. U.S.Department of Health and Human Services. Physical activity and health: a report of the surgeon general.Atlanta: U.S. Department of Health and Human Services, Centers for Disease Control and Prevention, National Center for Chronic Disease Prevention and Health Promotion, 1996. 6. Hernández B, Gortmaker SL, Golditz GA, Peterson KE, Laird NM, Parra-Cabrera S. Association of obesity with physical activity, television programs and other forms of video viewing among children in México City. Int J Obes 1999;23:845-854.

7. Manson J, Skerrett P, Greeland P,Vanlallie T.The escalating pandemics of obesity and sedentary lifestyle. Arch Intern Med 2004;164:249-258. 8. World Health Organization. Report of a Joint WHO/FAO Expert Consultation. Diet Nutrition and the Prevention of Chronic Diseases. WHO Technical Report Series 916. Geneva:WHO, 2003.

9. Toussaint $\mathrm{G}$. Patrones de dieta y actividad física en la patogénesis de la obesidad en el escolar urbano. Bol Med Hosp Infant Mex 2000;57(II):650-661.

10. Palma O y col. Metodología. En: Olaiz-Fernández G, Rivera-Dommarco J, Shamah-Levy T, Rojas R,Villalpando-Hernández S, Hernández-Avila M, et al. Encuesta Nacional de Salud y Nutrición 2006. Cuernavaca, México: Instituto Nacional de Salud Pública, 2006: 19-33.

II. Habicht JP. Estandarización de métodos epidemiológicos cuantitativos sobre el terreno. (Standardization of anthropometric methods in the field). PAHO Bull 1974; 76:375-384.

12. Cole T, Bellizi M. Establishing a standard definition for child overweight and obesity worldwide: international survey. BMJ 2000;320:1-6.

13. Booth ML.Assessment of physical activity:An international perspective. Res Q Exerc Sport 2000;7I(2):SI I4-SI 20.

14. Resano E, Méndez I, Shamah T, Rivera J, Sepúlveda J. Methods of the National Nutrition Survey 1999. Salud Publica Mex 2003:45 suppl 4: S558-S564.

15. Jackicic J, Polley B,Wing R.Accuracy of self-reported exercise and the relationship with weight loss in overweight women. Med Sci Sports Exerc 1998;30:634-638.

16. Irwin M,Ainsworth B, Conway J. Estimation of energy expenditure from physical activity measures: determinants of accuracy. Obes Res 2001;9:517-525.

17. Buchowski M, Townsend K, Chen K, Acra S, Sun M. Energy expenditure determined by self-reported physical activity is related to body fatness. Obes Res 1999;7:23-33.

18. Lichtman S, Pisarska K, Berman E, Pestone M, Dowling H, Offenbacher $E$, et al. Discrepancy between self-reported and actual caloric intake and exercise in obese subjects. N Engl J Med 1992;327:1893-1898. 19. Mahabir S, Baer DJ, Giffen C, Clevidence BA, Campbell WS, Taylor PR, et al. Comparison of energy expenditure estimates from 4 physical activity questionnaires with doubly labeled water estimates in postmenopausal women.Am J Clin Nutr 2006;84: 230-236. 